\title{
economia
} ensaios

\section{Modo de Transporte e Tempo de Comutação na Região Metropolitana de São Paulo}

Transportation Mode and Commuting Time in the Metropolitan Region of São Paulo

Resumo: Objetiva-se analisar a relação entre modo de transporte utilizado e tempo gasto no deslocamento casa-trabalho na RMSP. Supõe-se que regiões de residência e trabalho exerçam influência na decisão de modal de deslocamento. Os resultados mostram que: áreas com probabilidade elevada dos trabalhadores utilizarem transporte privado também apresentam elevada probabilidade de utilização de transporte coletivo; a escolha por transporte privado é atrelada ao nível de instrução e renda do trabalhador. Sugerem-se três alternativas para melhorias de acessibilidade: introdução de pedágios; aumento de faixas exclusivas para ônibus; em horários de pico, faixas exclusivas para carros com um número mínimo de ocupantes.

Palavras-chave: Tempo; Transporte; Comutação; Acessibilidade.

Classificação JEL: J22, O18, R23

\begin{abstract}
We aim to analyze the relationship among the mode of transportation and time spent on home-work commuting. It is assumed that the regions of residence and work have inflluence on decision of the modal of commuting. Results show that in areas with high probability of workers using private transportation, they also present a high probability of using public transportation. Choice for private transportation is linked to the worker level of education and income. Three alternatives are suggested for accessibility improvements: introduction of tolls; increase in exclusive bus lanes; at peak times, exclusive lanes for cars with a minimum number of passengers.
\end{abstract}

Keywords: Time; Transportation; Commuting; Accessibility. JEL Classification: J22, O18, R23

\footnotetext{
${ }^{1}$ Professor Titular I no Ibmec-MG. Email: luiz.gama@ professores.ibmec.edu.br.
}

${ }^{2}$ Professor Associado no Cedeplar/UFMG. Email: agolgher@gmail.com. 


\section{Introdução}

A alocação de tempo em atividades do cotidiano foi tema de estudos teóricos e empíricos nas últimas décadas (RIBEIRO, 2012; LE; MILLER, 2013). No caso de economia de transporte, Nelson (1977) destaca a importância da acessibilidade. A acessibilidade a locais de trabalhos apresenta diversas dimensões importantes, como tempo de deslocamento, segurança no trajeto, etc.

Uriarte (2012) destaca que o padrão de viagens depende de três componentes principais: do padrão do uso do solo; do desenho urbano; e do sistema de transporte. Desta forma, são diversos os fatores que exercem influência sobre modos de transportes utilizados nos centros urbanos. Entre estes, um sistema de transporte público de qualidade influencia diretamente nas escolhas por tipo de transporte. Ganhos de mobilidade tem influência positva em muitos quesitos, tais como: ganhos de produtividade, impactos positivos na saúde, redução de acidentes, além de impactos sobre o orçamento das famílias (HADDAD et al., 2015). O autor mostra como são importantes os investimentos nesta área em que, especificamente para a Região Metropolitana de São Paulo (RMSP), os ganhos trespassam as fronteiras da capital, beneficiando todo o entorno.

A forma como a expansão urbana ocorre pode levar a custos sociais que necessitam ser considerados, em que um caráter de desperdício de tempo pode emergir (CAMAGNI; GIBELLI; RIGAMONTI, 2002). Nos últimos anos, o padrão de mobilidade urbana mostrou alteração no Brasil, com aumento acelerado da taxa de motorização da população (CARVALHO; PEREIRA, 2013). Esse aumento pode resultar em maior número de acidentes de trânsito, maior poluição veicular e, com o aumento dos congestionamentos nos centros urbanos, em maior tempo gasto em deslocamentos.

O objetivo deste artigo é averiguar a relação entre o modo de transporte escolhido para a comutação, com o tempo gasto comutando entre os locais de residência e trabalho. A escolha do tipo de transporte depende de alguns fatores, sendo a distância um fator preponderante, assim como a renda disponível.

Para a consecução dos objetivos propostos, são utilizados dados da Pesquisa Origem-Destino (OD) para a Região Metropolitana de São Paulo (RMSP), para os anos de 2007 e 2012. Dada a interligação entre distância, tempo comutado e tipo de transporte, optou-se pela utilização de equações estruturais (SEM). Além disso, considerando-se que as zonas geográficas de origem e destino podem influenciar o tipo de transporte escolhido e, também, a duração do trajeto, optou-se por uma modelagem multinível. Assim, desejase identificar os determinantes da escolha por qual tipo de transporte utilizado e, também, os determinantes do tempo gasto até o trabalho.

Este artigo está dividido em cinco seções. Depois desta introdução, apresenta-se a revisão da literatura. Posteriormente, na terceira seção, a metodologia do trabalho é apresentada. Na quarta seção são apresentados os resultados. Por fim, são feitas as considerações finais do trabalho. 


\section{Literatura}

De acordo com Charron (2007), dois componentes principais fundamentam a comutação: i) o componente comportamental, que consiste na tolerância individual à comutação, em que o indivíduo almeja benefícios indirets, como melhores residências, maiores oportunidades de trabalho, etc.; ii) um componente morfológico, que é parte da forma urbana. $\mathrm{O}$ autor argumenta que o componente comportamental permite que exista comutação, porém não a impõe, ao passo que o componente morfológico impõe a existência de comutação no ambiente urbano.

Nelson (1977) destaca a importância da acessibilidade, definida como a recíproca dos custos de mover pessoas e bens entre pontos no espaço. Villaça (2001, p. 23) destaca que, no contexto urbano, a acessibilidade é mais importante para a produção de localizações do que a presença de infraestrutura. $\mathrm{O}$ autor afirma que "mesmo não havendo infraestrutura, uma terra jamais poderá ser considerada urbana se não for acessível - por meio do deslocamento diário de pessoas - a um contexto urbano e a um conjunto de atividades urbanas... e isso exige um sistema de transporte de passageiros".

Tendo em mente as questões morfológicas e de acessibilidade nos centros urbanos, vários fatores influenciam a decisão de um indivíduo por qual tipo de transporte escolher para comutar diariamente. É sabido que os custos de comutação, sejam estes pecuniários ou não pecuniários, são compensados por aluguéis reduzidos e/ou salários mais elevados (BOJE et al., 2010). Além disso, os custos com comutação crescem à medida que crescem a distância, tempo e dinheiro gastos com tal movimento.

Glaeser, Kahn e Rappaport (2008) desenvolvem um modelo de escolha de tipo de transporte. Analisando a situação nos Estados Unidos, os autores argumentam que os pobres, por não terem condições de obterem automóveis, precisam confiar no transporte público e os centros da cidade seriam as únicas áreas urbanas com densidade suficiente para fornecer um transporte público conveniente. Por isso, o padrão americano de pobres no centro e ricos nas periferias. Brueckner (2011) argumenta que este padrão não é sempre observado na Europa e também nos países latino americanos. Um dos motivos, segundo o autor, são as amenidades urbanas, além de um transporte público mais eficiente.

Dadas as mudanças pelas quais as grandes cidades passaram nos últimos anos (aumento significativo da frota de veículos, desenvolvimento de transporte público mais rápido, etc.), falar na questão de residências próximas ao centro de negócios, apenas, pode soar ultrapassado. Devem ser levadas em consideração, também, a proximidade de rodovias de fácil acesso ao trabalho e a proximidade da residência às estações de metrô, etc. Obviamente, o centro ainda mantém sua importância como polo de negócios e residir perto pode ser considerado uma vantagem. O ponto aqui é que outras questões também devem ser levadas em consideração (NÆSS, 2005).

Næss (2005) trata do conceito de "recursos de mobilidade" ao analisar escolha por tipos de transporte. Tais recursos dependem das qualificações e habilidades do indivíduo (ex. posse de carteira de motorista), dos recursos financeiros (posse de veículo automotor, 
dinheiro para a gasolina ou para pagamento de transporte público, etc.), valores e atitudes próprias (o indivíduo pode ser contra a poluição excessiva dos veículos e optar por comutar de bicicleta) e também pela necessidade de transporte. Se o indivíduo morar a 30 $\mathrm{km}$ de sua residência, dificilmente optará por utilizar bicicleta, por exemplo. Outro fator que pode interferir na escolha de transporte é o horário.

Dentre essas variáveis, é evidente que a posse de veículo automotor é importante na determinação do modo de transporte diário. No contexto urbano, a posse de veículo está associada em parte ao ambiente construído (built environment - BE), como aponta Zegras (2010). Como exemplo, a disponibilidade de vias de fácil acesso e circulação, assim como a densidade no local, influenciam a escolha por um modo de deslocamento.

Com a descentralização das cidades, ocorrida nos últimos anos, cresceu o uso de veículos automotores e, ao mesmo tempo, a duração das viagens também cresceu (NIJKAMP; RIENSTRA, 1996). Com isto, ganhou força na literatura, a concepção de cidade compacta (compact city): moradias são providas em áreas com densidades relativamente altas e trabalhos são concentrados nos centros das cidades e em um número limitado de sub-centros. Tal ideia recebe variadas críticas, pois sua concepção levaria a uma intervenção excessiva do Estado sobre o planejamento das cidades.

Na contramão desse conceito, Masser, Svidén e Wegener (1992) abordam a questão da suburbanização das moradias. De acordo com os autores, esta seria consequência de fatores como aumento da renda, menor tamanho das famílias, mais tempo de lazer, e mudanças nas preferências por moradias maiores. Porém, suburbanização é geralmente associada a questões negativas, como longas viagens para trabalho e compras, maior consumo de energia, poluição, acidentes e problemas de provisão de transporte público em áreas de baixa densidade. A suburbanização das moradias, de acordo com Breheny (1995), leva subsequentemente à suburbanização do emprego. Portanto, tanto residências quanto postos de trabalho tendem a se dispersar dos centros urbanos para uma área metropolitana mais ampla, ao que Breheny dá o nome de suburbanização estendida ou contra-urbanização. No Brasil podem-se citar vários trabalhos que tratam do tema, dos mais variados enfoques, como Villaça (2001), Cruz (2007), Ojima et al. (2010), entre outros.

Com base na literatura sobre o tema, algumas observações podem ser feitas. Primeiramente, vários estudos mostram que, entre os indivíduos que vivem mais próximos dos centros urbanos, a distância comutada é menor e também a utilização de carro é mais reduzida do que aqueles que residem nos subúrbios (MOGRIDGE, 1985; NÆSS; JENSEN, 2004). Boje et al. (2010) encontram que, em média, os comutadores de maiores distâncias são mais qualificados. Se este é o caso para o Brasil, espera-se que aqueles que mais comutam sejam os que utilizem veículos, pois dada a maior renda, eles possuem mais fácil acesso. Porém, o veículo automotor pode levar a uma diminuição do tempo comutado, por isso a importância de também se considerar a distância percorrida de forma a controlar o efeito da escolha de determinado modo de transporte sobre o tempo de comutação. 
Com o intuito de se analisar os determinantes da escolha do tipo de model de transporte e a relação com o tempo de deslocamento em centros urbanos foi selecionada a RMSP. Além de ser a maior metrópole do Brasil, ela dispõe da base de dados OrigemDestino (OD), que permitiu a confecção desse estudo. Na próxima seção é apresentada uma breve descrição da RMSP.

\section{Metodologia}

\subsection{Dados}

Os dados utilizados neste artigo são oriundos da Pesquisa Origem e Destino (OD) da RMSP, para 2007 e, da Pesquisa de Mobilidade de 2012. Foi exatamente na RMSP onde foi realizada a primeira Pesquisa OD no país, em 1967, e o intuito era a obtenção de dados para os estudos e projetos da rede básica do metrô. Posteriormente, mais seis pesquisas foram realizadas: em 1977, em 1987, em 1997, em 2002, em 2007 e em 2012. Optou-se por utilizar as pesquisas de 2007 e 2012 por serem as mais recentes, sendo que a área da RMSP não variou no período.

Na Pesquisa OD 2007, a RMSP é dividida em 460 zonas - 320 na capital -, sendo visitados 30.000 domicílios e aproximadamente 120.000 indivíduos foram entrevistados.

Foram selecionados os indivíduos que comutaram por motivo trabalho, com idade entre 21 e 65 anos e renda positiva. A intenção é analisar uma amostra de indivíduos em idade de trabalhar. Os mais jovens e mais velhos, em muitos casos, quando ocupados, tendem a realizar trabalhos em jornada parcial, pois têm que conciliar com os estudos, no caso dos jovens, e, no caso dos mais velhos, são aposentados que trabalham almejando um incremento de renda.

Uma última correção foi necessária na amostra original. Alguns indivíduos reportaram duração do deslocamento discrepante com a distância e o modo de transporte principal utilizado. Com isso, foi feita uma seleção na amostra com base na velocidade do deslocamento e o modal utilizado. Foram excluídos indivíduos que declararam deslocamentos a pé com velocidade acima de $15 \mathrm{~km} / \mathrm{h}$ (265 observações excluídas), indivíduos comutando de bicicleta com velocidade acima de $30 \mathrm{~km} / \mathrm{h}$ (8 observações), trabalhadores via transporte coletivo com velocidade acima de $80 \mathrm{~km} / \mathrm{h}$ (18 observações) e, por fim, os trabalhadores que utilizaram transporte privado individual com velocidade acima de $110 \mathrm{~km} / \mathrm{h}$ (32 observações). A amostra final conta com 28.197 observações.

A Pesquisa de Mobilidade 2012 da RMSP fez levantamento de dados em 8.115 domicílios em 31 zonas agregadas, sendo coletado dados de 53.500 indivíduos. O mesmo tratamento dos dados, feito em 2007, também foi feito em 2012. Após as exclusões supracitadas, a amostra conta com 8.194 trabalhadores.

A defasagem temporal entre as duas pesquisas deve-se ao fato de a Pesquisa OD ir a campo a cada cinco anos. Até o momento da consecução do presente trabalho, as duas pesquisas eram as mais recentes. 
Por fim, os modos de transporte considerados foram agregados da seguinte forma: i) modo coletivo - metrô, trem, ônibus, transporte fretato e transposte escolar; ii) modo individual - táxi, automóvel (motorista ou passageiro) e motocicleta; iii) modo não motorizado - bicicleta e a pé.

\subsubsection{Variáveis}

No Quadro 1 são apresentadas as variáveis utilizadas para consecução das estimativas e também das estatísticas descritivas. Para efeitos de comparação, para os dois anos estudados, as variáveis escolhidas são as mesmas.

\section{Quadro 1: Variáveis Utilizadas nas Descrições e Estimativas}

\begin{tabular}{|c|c|}
\hline Variável & Descrição \\
\hline \multicolumn{2}{|r|}{ Variáveis dependentes } \\
\hline Modo de deslocamento & $\begin{array}{l}\text { Define se o trabalhador vai para o trabalho de transporte não motorizado; se o } \\
\text { trabalhador utiliza transporte coletivo; ou se utiliza transporte individual privado. }\end{array}$ \\
\hline Tempo de deslocamento & Tempo de ida para o trabalho em minutos. \\
\hline \multicolumn{2}{|r|}{ Variáveis independentes ( $\left(1^{\circ}\right.$ nível) } \\
\hline Distância & Distância em quilômetros entre o local de residência e de trabalho. \\
\hline Horário de ida ao trabalho & $\begin{array}{l}\text { Define se o trabalhador comuta fora dos horários de pico; se comuta entre } 6 \text { e } 10 \\
\text { horas da manhã; ou se comuta entre } 17 \text { e } 20 \text { horas. }\end{array}$ \\
\hline Pendular & Define se o trabalhador vive em município distinto do de trabalho. \\
\hline Capital & Define se o trabalhador reside na capital paulista. \\
\hline Sexo & Define o sexo do indivíduo. \\
\hline Idade & Idade em anos. \\
\hline Instrução & $\begin{array}{l}\text { Define se o trabalhador possui até o ensino fundamental incompleto; se possui } \\
\text { fundamental completo ou ensino médio incompleto; se possui ensino médio } \\
\text { completo ou superior incompleto; ou se possui pelo menos o ensino superior } \\
\text { completo. }\end{array}$ \\
\hline Sit. Família & $\begin{array}{l}\text { Define se o trabalhador é o responsável pela família; se é o cônjuge ou } \\
\text { companheiro; se é filho(a), ou outros. }\end{array}$ \\
\hline Renda & Renda mensal domiciliar. \\
\hline \multicolumn{2}{|r|}{ Variáveis independentes $\left(2^{\circ}\right.$ nível) } \\
\hline Zona_dom & Zona geográfica de residência \\
\hline
\end{tabular}

Fonte - Elaboração própria.

Os modos de deslocamento apresentados no Quadro 1 são agrupados em três categorias: transporte não motorizado; transporte coletivo; ou transporte individual privado. O tempo de deslocamento de ida ao trabalho é dado em minutos, sendo que, nas estimações, utiliza-se seu logaritmo natural. 
Espera-se que quanto maior a distância menor a probabilidade de escolha de transporte não motorizado e maior o tempo gasto com o deslocamento. Opta-se pela inclusão da variável "Horário" em razão de sua importância tanto na determinação do modal de viagem utilizado quanto sobre a duração dos deslocamentos. Sabe-se que a maior concentração de veículos, gerando lentidão do tráfego, ocorre nos horários de pico da manhã e da tarde, pois nestes horários a grande maioria dos trabalhadores está se deslocando.

Migrantes pendularescomutam maiores distâncias, em média, e devem atravessar pelo menos uma fronteira municipal, o que pode ter consequências tanto no desenho urbano mais fragmentado como na provisão de transporte público. Logo, espera-se que as escolhas por modo de transporte sejam distintas entre pendulares e não pendulares.

Sexo, idade, grau de instrução e situação na família são características demográficas que, de forma geral, afetam as decisões dos indivíduos. Por exemplo, parte da literatura afirma que mulheres trabalham mais próximas de suas residências (LEVY, 2013), parte afirma que o tempo de comutação médio de homens e mulheres é similar (KWAN, 2000), mesmo morando mais próximas, ou seja, homens comutam em maior velocidade (QUIROS; MEHNDIRATTA; OCHOA, 2014). Indivíduos mais velhos podem ser menos propensos a caminharem ou comutarem de bicicleta (PLAUT, 2005). O chefe do domicílio pode ser o único que utiliza veículo automotor (QUIROS; MEHNDIRATTA; OCHOA, 2014), etc.

Os valores da variável "Renda" foram deflacionados pelo Índice Nacional de Preços ao Consumidor (INPC), para os patamares de outubro de 2012. Espera-se que a posse e o uso de transporte privado sejam positivamente correlacionados com a renda.

Por fim, a variável "Zona_dom" define o segundo nível nos modelos hierárquicos, explicitados na próxima subseção. A importância destas características reside no fato de que o built enviroment de uma zona geográfica específica pode afetar tanto o modo de transporte utilizado (por exemplo, disponibilidade de ônibus ou ciclo faixas para bicicletas), quanto o tempo comutado (por exemplo, vias de fácil acesso podem facilitar o transporte privado e diminuir o tempo comutado). Neste sentido, as observações em determinada zona geográfica podem ser correlacionadas. Como os resultados são similares, optou-se por apresentar os resultados somente considerando as zonas de residência.

\subsection{Estratégia Econométrica}

\subsubsection{Modelagem Hierárquica}

A modelagem multinível é aplicada nos casos em que os dados são oriundos de populações com estruturas complexas (RASBASH, 2008). No presente trabalho, dois níveis são considerados. No menor nível de desagregação (nível 1 - individual), a variável dependente é mensurada. As variáveis explicativas podem ser especificadas no primeiro 
nível ou no nível mais elevado (nível 2 - zona geográfica de residência). Baseado em Tabachnick e Fidell (2007), destacam-se duas vantagens da aplicação de um modelo hierárquico: não há necessidade de independência dos erros e evita-se a chamada falácia ecológica, que ocorre ao interpretar resultados agregados no nível individual, confundidose efeitos individuais com efeitos agregados.

A estrutura é baseada na suposição de correlação nos dados, de modo que os indivíduos dentro de uma mesma área ou zona geográfica tendem a ser mais similares (STEELE, 2008). Esta hipótese é razoável, pois características específicas da área de residência - como distância até o centro, congestionamentos, etc. - podem influenciar no tipo escolhido de transporte pelo trabalhador. No modelo hierárquico, além de esperada, a correlação nos erros é explicitamente modelada.

\subsubsection{Modo de Transporte}

Com relação ao modo de transporte, abaixo é apresentado um quadro resumo de algumas metodologias.

\section{Quadro 2: Escolha do Modo de Transporte}

\begin{tabular}{|l|l|l|}
\hline \hline \multicolumn{1}{|c|}{ Artigo } & \multicolumn{1}{|c|}{ Metodologia } & \multicolumn{1}{|c|}{ Principais resultados } \\
\hline $\begin{array}{l}\text { Glaeser, Kahn } \\
\text { e Rapport } \\
(2008)\end{array}$ & $\begin{array}{l}\text { Aplicação de MQO e Variáveis instrumentais, no } \\
\text { intuito de analisar a elasticidade-renda da demanda } \\
\text { por terra entre indivíduos pobres e ricos, assim } \\
\text { como a escolha por tipo de transporte. }\end{array}$ & $\begin{array}{l}\text { Elasticidade não é tão importante para } \\
\text { explicar pobreza urbana. Melhor acesso a } \\
\text { tranporte público sim. }\end{array}$ \\
\hline $\begin{array}{l}\text { Haddad } \text { et al. } \\
(2015)\end{array}$ & $\begin{array}{l}\text { Exercício de simulação usando um modelo de } \\
\text { equilibrio geral espacial, para a região } \\
\text { metropolitana de São Paulo. }\end{array}$ & $\begin{array}{l}\text { Concluem que o modo de transporte via } \\
\text { metrô traz beneficios não apenas para os } \\
\text { residentes da cidade de São Paulo, mas } \\
\text { também para todo o entorno. }\end{array}$ \\
\hline $\begin{array}{l}\text { Hensher e Rose } \\
(2007)\end{array}$ & $\begin{array}{l}\text { Trabalho teórico de simulação de escolha de modo } \\
\text { de transporte, usando modelos nested logit. }\end{array}$ & $\begin{array}{l}\text { Além de modelos de escolha discreta, os } \\
\text { autores concluem que modelos em que os } \\
\text { dados são sobre preferência revelada dos } \\
\text { indivíduos também deveriam ser aplicados. }\end{array}$ \\
\hline Zegras (2010) & $\begin{array}{l}\text { Utilizam o modelo logit multinomial para avaliar a a } \\
\text { escolha de modal de transporte motor pelas } \\
\text { famílias. }\end{array}$ & $\begin{array}{l}\text { Renda é o principal determinante da escolha } \\
\text { pela posse de veículos automotores. } \\
\text { Entretanto, outras variáveis, como } \\
\text { características familiares e da região de } \\
\text { residência também ajudam a explicar a } \\
\text { escolha. }\end{array}$ \\
\hline \hline
\end{tabular}

Fonte: Elaboração própria.

No presente trabalho, para a análise da escolha do tipo de transporte, aplica-se o modelo logit multinomial hierárquico, sob a suposição de que a probabilidade de o trabalhador escolher certo tipo de transporte difere de acordo com sua área de residência.

A variável dependente assume os seguintes valores: i) valor 1: se o indivíduo não utiliza transporte motorizado, ou seja, caminha ou utiliza bicicleta para o trabalho; ii) valor 2: se o modo de transporte é coletivo; iii) valor 3: se o trabalhador utiliza transporte 
individual privado. A especificação do modelo consiste em uma estrutura em dois níveis onde o total de trabalhadores $i$ (nível 1) são aninhados com as $j$ áreas de residência (nível 2). O modelo logit multinomial, considerado em sua forma generalizada, com a categoria 1 como referência, e, com um intercepto aleatório, pode ser observado na Equação 1:

$$
\log \left(\frac{\pi_{k i j}}{\pi_{l i j}}\right)=\beta_{0 k}+\beta_{1 k} X_{i j}+\mu_{k j}, \quad k=2,3
$$

onde $\frac{\pi_{k i j}}{\pi_{l i j}}$ representa o contraste entre a probabilidade do indivíduo $i$, pertencente à zona geográfica $j$ responder $k$ em relação à resposta $l$. $\beta_{0 k}$ é o intercepto global na relação linear entre a log-odds e $X_{i j}$. $\mu_{k j}$ é o efeito aleatório de segundo nível da comparação da categoria $k$ com relação à categoria de referência. $O$ parâmetro $\beta_{1 k}$ mede o efeito da mudança em $X$ nas chances de escolher a alternativa $k$ ao invés da alternativa $l$, ajustad pelos efeitos de grupo.

Os efeitos aleatórios $\mu_{k j}$ permitem que as probabilidades de resposta variem entre grupos. Especificamente, se $\mu_{k j}>0$, significa que um indivíduo pertencente ao grupo $j$ possui chances acima da média de responder $k$ ao invés de $l$, e vice-versa. A variância entre grupos é representada por $\sigma_{\mu k}{ }^{2}$. A covariância de segundo nível $\left(\sigma_{\mu k l}\right)$ é positiva se grupos com altas (baixas) chances de responderem $k$, em detrimento de 1 , também tiverem altas (baixas) chances de responderem $l$, também em detrimento de 1 . Logo, a covariância é positiva quando as categorias $k$ e $l$ apresentam similaridades de alguma forma e compartilham efeitos de segundo nível não mensuráveis (STEELE, 2013).

O modelo Logit Multinomial impõe um pressuposto forte: a independência das alternativas irrelevantes (IIA assumption). Esse pressuposto significa que, tudo o mais permanecendo constante, se uma pessoa tem que escolher entre duas alternativas, sua escolha relativa não é afetada se uma outra escolha estiver disponível. Como afirmam Dahlberg e Eklöf (2003), não pode haver similaridades entre as alternativas. Caso exista essa similaridade, e esta for devido, pelo menos em parte, a características não mensuradas, permitir a correlação residual no segundo nível (dando origem ao termo de covariância), ajuda no relaxamento da IIA assumption. Entretanto, como afirmam Chen, Liu e Li (2013), a aplicação de uma metodologia aninhada, como no presente trabalho, ajuda no relaxamento dessa hipótese.

\subsubsection{Tempo de Comutação}

Nesta segunda modelagem, a variável dependente é o tempo de deslocamento até o trabalho, sendo permitidas diferenças de grupo para a média da variável dependente. Baseado em Steele (2008), o modelo hierárquico, com intercepto aleatório e coeficiente aleatório, pode ser considerado da seguinte forma:

$$
y_{i j}=\beta_{0}+\beta_{1} X_{i j}+\mu_{0 j}+\mu_{i j} X_{i j}+\varepsilon_{i j}
$$


onde $y_{i j}$ é o tempo comutado do indivíduo $i$, pertencente à zona $j$. $\beta_{0}$ é o intercepto global (entre grupos) e $\beta_{1}$ representa a relação global entre $X_{i j}$ e $y_{i j}$. O intercepto para um grupo específico $j$ é $\beta_{0}+\mu_{j}$, podendo ser maior ou menor do que o intercepto global. Assume-se que os efeitos aleatórios, $\mu_{0 j}$ e $\mu_{1 j}$, apresentem distribuições normais, com médias zero,

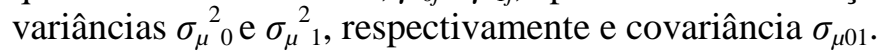

\subsubsection{Modelo de Equações Estruturais Generalizado (GSEM)}

No aracabouço das ciências sociais, SEM são métodos que permitem análises não possíveis com outros métodos ou análises mais robustas (WERNER; SCHERMELLEHENGEL, 2009). Seguindo os autores, podem ser apontadas como vantagens: i) validade, dado que o método SEM permite utilizar várias variáveis indicadoras simultaneamente para construção do modelo; ii) com relação a erros de mensuração, a modelagem permite a inclusão explícita de variáveis que dão conta de tal problema, evitando viés na construção da relação entre as variáveis; iii) modelos complexos, sendo a principal vantagem para o principal trabalho. Assim, os modelos SEM permitem construir e testar padrões complexos de relações, incluindo várias hipóteses simultanemante.

A relação entre as variáveis consideradas é dada como na Figura 1. Nos diagramas que denotam modelos estruturais, variáveis dentro de retângulos são observadas e variáveis no interior de círculos são latentes. Quando uma seta parte de uma variável para outra, significa que a primeira afeta a segunda. Dada a sequencialidade de determinação entre o tempo de deslocamento e o tipo de veículo utilizado (o indivíduo escolhe o modo de transporte concomitante ao tempo que espera gastar), assume-se que os termos de erro sejam correlacionados.

A variável Tipo de veículo possui três categorias, das quais uma é omitida na estimativa

(Modo não motorizado). Por este motivo ela não é representada no diagrama da Figura 1. A variável Zona, além de ser latente - não diretamente observável -, está em um nível superior às demais (nível 2), por isso está representada por dois círculos.

Os efeitos aleatórios são separados, por isso cinco círculos. Os efeitos Zonale Zona2 são referentes ao modelo logit hierárquico e, são correlacionados, sendo na imagem esta correlação representada pela seta com duplo caminho. Ambos são interceptos aleatórios.

Os efeitos aleatórios Zona3, Zona4 e Zona5 são referentes à estimativa do tempo gasto até o trabalho. Zona3 é um intercepto aleatório. Já os termos Zona4 e Zona5 tratamse de coeficientes aleatórios, por isso a seta aponta para o caminho entre o Modo Coletivo e Tempo (Zona4) e para o caminho entre o Modo Individual e Tempo (Zona5). Assume-se que os três termos são correlacionados, por isso há setas os conectando.

Primeiramente, estima-se o modelo por escolha de transporte para cada ano. Dado que a escolha do tipo de transporte, leva, posteriormente, a diferentes tempos comutados, o valor predito de cada escolha é utilizado na equação cuja variável dependente é o tempo de deslocamento. 
Porém, em modelos de dois estágios, como afirmam Cameron e Trivedi (2005), para inferências estatísticas validas, é necessário ajustar a variância assintótica do segundo estágio. Caso não seja feito, os erros-padrão do segundo estágio são enviesados. Por isso, opta-se por realizar estimação via bootstrap nos dois estágios, com 200 replicações (Efron e Tibshirani, 1994).

Figura 1: Diagrama de Caminho entre as Respostas

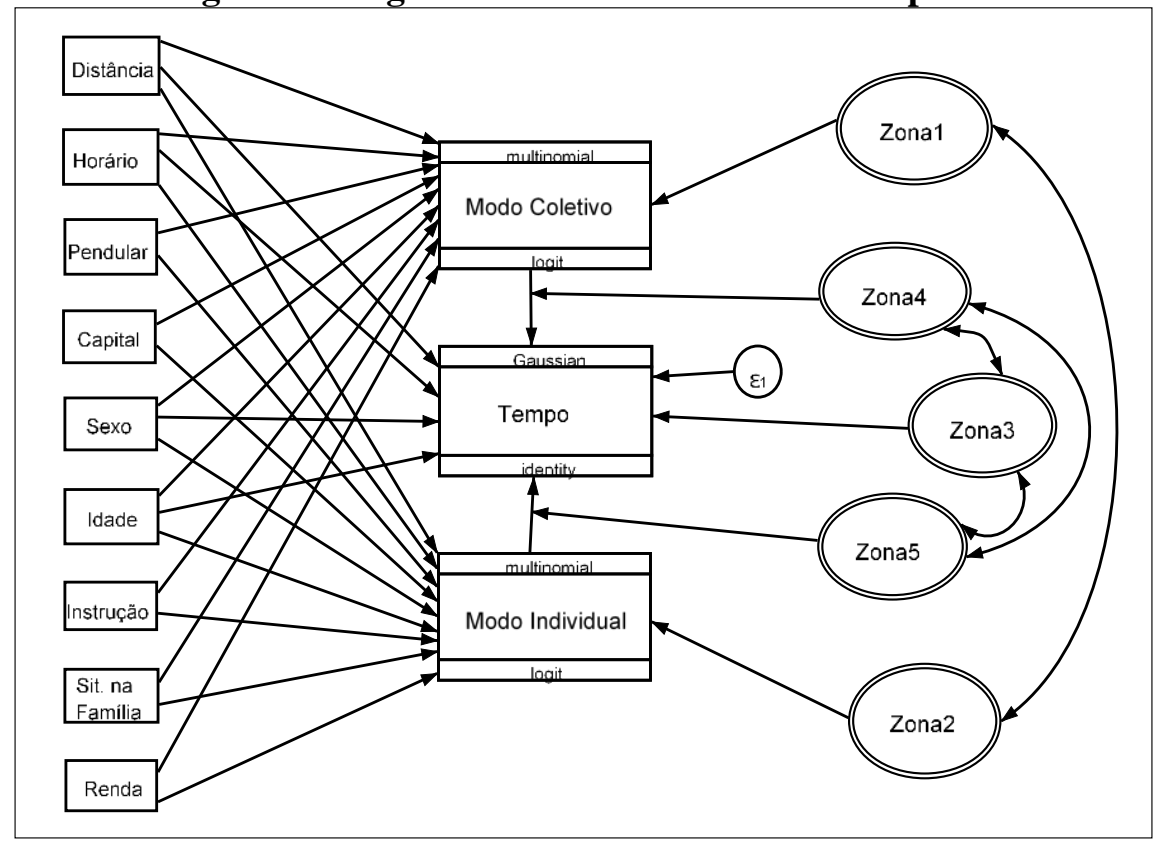

Fonte: Elaboração própria

\section{Resultados}

Na Tabela 1 são apresentadas descrições para ambos os anos estudados. Houve, no período, crescimento real da renda domiciliar em torno de $3 \%$. Outro dado interessante é o crescimento do percentual de mulheres no mercado de trabalho, considerando nossa amostra (mais de um ponto percentual). Houve crescimento da taxa de posse de veículos por domicílio - tanto de motos quanto de carros. Com relação ao modal de transporte utilizado, percebe-se um crescimento da preferência pelo transporte privado, em detrimento do transporte público e também do não motorizado.

Tabela 1: Estatísticas Descritivas

\begin{tabular}{l|c|c|c}
\hline \hline \multicolumn{1}{c|}{ Categoria } & Descrição & $\mathbf{2 0 0 7}$ & $\mathbf{2 0 1 2}$ \\
\hline Socioeconômica & Média de renda domiciliar & 3,621 & 3,733 \\
\hline
\end{tabular}




\begin{tabular}{l|c|c|c}
\multirow{4}{*}{$\begin{array}{l}\text { Demográfica e posse de } \\
\text { auto }\end{array}$} & Idade média & 37,33 & 38,56 \\
\cline { 2 - 4 } & Percentual de mulheres & 42,73 & 44,09 \\
\cline { 2 - 4 } & Número de carros por domicílio & 0,79 & 0,82 \\
\cline { 2 - 4 } & Número de motos por domicílio & 0,11 & 0,13 \\
\hline \multirow{3}{*}{ Modal de transporte (\%) } & Privado & 32,22 & 34,36 \\
\cline { 2 - 4 } & Público & 51,33 & 49,91 \\
\cline { 2 - 4 } & A pé ou bicicleta & 16,45 & 15,72 \\
\hline \hline
\end{tabular}

Fonte - Elaboração própria a partir dos dados das Pesquisas OD.

Na Tabela 2, são apresentadas estatísticas descritivas para as variáveis de controle das estimativas, divididas por modos de deslocamento. As distâncias médias comutadas mais elevadas se encontram entre os trabalhadores que utilizam como transporte principal o público. Analisando os horários de deslocamento, observa-se que em ambos os anos há elevada proporção de utilização de transporte coletivo fora dos horários de pico, enquanto nos horários de pico crescem os percentuais de utilização de modo privado individual.

Tabela 2: Estatísticas Descritivas - Modo de Transporte

\begin{tabular}{|c|c|c|c|c|c|c|}
\hline & \multicolumn{3}{|c|}{2007} & \multicolumn{3}{|c|}{2012} \\
\hline Variável & Não Mot. & Coletivo & Individual & Não Mot. & Coletivo & Individual \\
\hline Distância (média) & 1065,09 & 12384,64 & 8289,54 & 908,38 & 12069,59 & 8411,66 \\
\hline \multicolumn{7}{|c|}{ Horário do deslocamento (\%) } \\
\hline Fora do pico & 12,85 & 64,07 & 23,08 & 13,35 & 60,64 & 26,01 \\
\hline Entre 6 e 10 horas da manhã & 18,39 & 44,83 & 36,78 & 16,94 & 44,47 & 38,59 \\
\hline Entre 17 e 20 horas & 13,17 & 55,80 & 31,03 & 15,42 & 50,15 & 34,43 \\
\hline \multicolumn{7}{|c|}{ Migrante Pendular? (\%) } \\
\hline Não & 20,89 & 47,63 & 31,48 & 20,04 & 46,48 & 33,48 \\
\hline Sim & 2,40 & 63,04 & 34,55 & 2,00 & 60,84 & 37,16 \\
\hline \multicolumn{7}{|l|}{ Vive na Capital? (\%) } \\
\hline Não & 18,45 & 49,06 & 32,48 & 16,16 & 47,30 & 36,54 \\
\hline Sim & 15,06 & 52,91 & 32,03 & 15,41 & 51,79 & 32,80 \\
\hline Sexo & & & & & & \\
\hline Feminino & 19,78 & 57,75 & 22,47 & 18,46 & 58,11 & 23,43 \\
\hline Masculino & 13,97 & 46,54 & 39,49 & 13,56 & 43,45 & 42,99 \\
\hline \multicolumn{7}{|c|}{ Grau de Instrução (\%) } \\
\hline Até ensino primário incompleto & 22,92 & 55,71 & 21,37 & 20,36 & 58,40 & 21,24 \\
\hline $\begin{array}{l}\text { Primário completo e até } \\
\text { fundamental incompleto }\end{array}$ & 23,85 & 52,30 & 23,84 & 24,76 & 50,42 & 24,82 \\
\hline $\begin{array}{l}\text { Fundamental completo e até médio } \\
\text { incompleto }\end{array}$ & 22,42 & 53,33 & 24,25 & 20,07 & 52,37 & 27,55 \\
\hline $\begin{array}{l}\text { Médio completo e até superior } \\
\text { incompleto }\end{array}$ & 14,13 & 56,44 & 29,43 & 14,11 & 54,49 & 31,40 \\
\hline Superior completo ou mais & 8,90 & 35,82 & 55,27 & 9,16 & 36,23 & 54,61 \\
\hline \multicolumn{7}{|c|}{ Situação Familiar (\%) } \\
\hline Pessoa responsável pelo domicílio & 16,07 & 47,37 & 36,56 & 16,18 & 43,65 & 40,16 \\
\hline Cônjuge/Companheiro(a) & 20,33 & 51,63 & 28,04 & 19,42 & 54,30 & 26,28 \\
\hline Filho(a)/Enteado(a) & 12,69 & 57,27 & 30,04 & 10,92 & 57,01 & 32,08 \\
\hline Outro & 21,64 & 54,69 & 23,67 & 16,50 & 58,02 & 25,48 \\
\hline
\end{tabular}


Fonte - Elaboração própria a partir dos dados.

Migrantes pendulares possuem proporções de utilização de transporte coletivo e privado superiores aos não migrantes, com destaque para o primeiro. Isso ocorre, pois é muito baixa a proporção de pendulares que comutam a pé ou de bicicleta. Residentes da capital utilizam mais transporte público para deslocamento casa-trabalho que residentes do entorno. Isso porque comutam menos a pé ou de bicicleta, apesar de a diferença ter caído no período. Os percentuais de utilização de veículo privado são similares, em 2007. Entretanto, em 2012, o crescimento proporcional da utilização de veículo privado foi maior no entorno do que na capital.

Para ambos os anos, percebe-se um padrão em que homens, em comparação às mulheres, utilizam menos transportes público e não motorizado e mais transporte privado. Para ambos os anos, quanto maior a educação formal de um trabalhador, menor a proporção daqueles que comutam a pé ou de bicicleta para o trabalho. Com relação à utilização de transporte coletivo, diferenças significativas só surgem quando comparamos trabalhadores com ensino superior ao restante da amostra. Inclusive, em 2007, a maior proporção de utilização de transporte público está entre aqueles com ensino médio completo ou ensino superior incompleto. Em 2012 esse posto pertence aos menos escolarizados da amostra $(58,4 \%)$. À medida que cresce a escolaridade cresce também a utilização de veículo privado para o deslocamento. Indivíduos mais escolarizados recebem, em média, maiores rendimentos, o que permite uma maior gama de escolhas.

Na Tabela 3 são apresentadas as médias de tempo gasto e distâncias médias, para cada uma das variáveis de controle. Um resultado que a princípio parece contraditório é que trabalhadores que se deslocam fora dos horários de pico gastam, em média, mais tempo no trajeto, em ambos os anos. A explicação passa pela distância e pelo modo de transporte. Esses trabalhadores vivem, em média, mais distantes de seus trabalhos e utilizam em maior proporção o transporte coletivo. Portanto, ou optam por comutarem fora do horário de pico para minimizar a já desgastante comutação, ou, são forçados a comutarem em tais horários, pois do contrário se atrasariam.

Como esperado, migrantes pendulares incorrem em maiores distâncias diariamente e, atrelado ao fato de utilizarem mais transporte público, apresentam tempo médio de deslocamento bem superior aos não pendulares. Em média, pessoas que vivem na capital paulista gastam mais tempo comutando que residentes do entorno, apesar da distância ser inferior em ambos os anos.

A análise por gênero mostra que houve mudanças no período. Homens e mulheres apresentam, em 2007, médias de tempo gasto similares, mesmo os homens incorrendo em maiores trajetos (KWAN, 2000) - homens utilizam mais veículo privado (TABELA 2). Entretanto, como em 2012 a distância média comutada pelos homens caiu $(1,87 \%)$ e a distância comutada pelas mulheres subiu (1,23\%), as mulheres passaram a gastar, em média, quase 3 minutos a mais que os homens no deslocamento casa-trabalho.

Em média, pessoas mais escolarizadas comutam menores distâncias, utilizam mais veículo privado e, consequentemente, gastam menos tempo no trajeto casa-trabalho. Os trabalhadores que mais gastam tempo com comutação são exatamente os com menor 
educação formal. Esses trabalhadores sofrem um tipo de double burden: são privados de renda e também de tempo. Como agravante, houve piora no período analisado, tendo o tempo médio de comutação crescido para este grupo em quase oito minutos (aumento de $13 \%$ em apenas cinco anos).

Por fim, apesar dos responsáveis pelo domicílio apresentarem elevada proporção e utilização de veículos privados, como pode ser visto na Tabela 3, estes comutam, em média, maiores distâncias que os cônjuges. Como resultado, não existem diferenças expressivas em termos de tempo comutado quando comparam-se esses dois grupos.

Tabela 3: Estatísticas Descritivas - Tempo de Deslocamento e Distância Média

\begin{tabular}{|c|c|c|c|c|}
\hline \multirow{2}{*}{$\begin{array}{l}\text { Variável } \\
\end{array}$} & \multicolumn{2}{|c|}{ Tempo médio de deslocamento } & \multicolumn{2}{|c|}{ Distância média } \\
\hline & 2007 & 2012 & 2007 & 2012 \\
\hline \multicolumn{5}{|l|}{ Horário do deslocamento } \\
\hline Fora do pico & 64,90 & 62,09 & 11291,47 & 10932,59 \\
\hline Entre 6 e 10 horas da manhã & 48,94 & 49,22 & 8180,80 & 8249,72 \\
\hline Entre 17 e 20 horas & 52,37 & 49,30 & 9054,78 & 8340,51 \\
\hline \multicolumn{5}{|l|}{ Migrante Pendular? } \\
\hline Não & 48,91 & 47,65 & 7433,99 & 7153,20 \\
\hline Sim & 70,77 & 71,71 & 14811,47 & 15392,89 \\
\hline \multicolumn{5}{|l|}{ Vive na Capital? } \\
\hline Não & 51,03 & 51,65 & 9243,14 & 9380,36 \\
\hline Sim & 56,33 & 54,68 & 9174,50 & 8942,45 \\
\hline \multicolumn{5}{|l|}{ Sexo } \\
\hline Feminino & 54,33 & 54,93 & 8356,68 & 8459,20 \\
\hline Masculino & 54,02 & 52,22 & 9834,05 & 9650,93 \\
\hline \multicolumn{5}{|l|}{ Grau de Instrução } \\
\hline Até ensino primário incompleto & 58,67 & 66,30 & 9691,14 & 10199,25 \\
\hline $\begin{array}{l}\text { Primário completo e até fundamental } \\
\text { incompleto }\end{array}$ & 55,42 & 53,32 & 8842,93 & 8639,96 \\
\hline Fundamental completo e até médio incompleto & 54,16 & 53,63 & 9210,73 & 8759,66 \\
\hline Médio completo e até superior incompleto & 55,55 & 53,44 & 9466,52 & 9317,29 \\
\hline Superior completo ou mais & 48,47 & 50,51 & 8698,59 & 9088,71 \\
\hline \multicolumn{5}{|l|}{ Situação Familiar } \\
\hline Pessoa responsável pelo domicílio & 53,22 & 52,22 & 9404,57 & 9372,74 \\
\hline Cônjuge/Companheiro(a) & 52,29 & 52,22 & 8189,44 & 8142,34 \\
\hline Filho(a)/Enteado(a) & 57,47 & 57,12 & 9822,90 & 9652,43 \\
\hline Outro & 53,56 & 53,59 & 8592,08 & 8779,50 \\
\hline
\end{tabular}

Fonte - Elaboração própria a partir dos dados.

\subsection{Estimativas - Modo de Transporte Utilizado}

Primeiramente, estima-se a escolha por transporte, considerando-se interceptos aleatórios (Equação 1). Os resultados são apresentados na Tabela 4. Apenas um intercepto aleatório foi incluído para cada escolha, não sendo introduzidos coeficientes aleatórios. Os coeficientes do primeiro nível foram exponencializados, ou seja, a interpretação se dá pela razão de riscos relativos. 
Em todos os modelos estimados, ao se aplicar o teste da razão de verossimilhança (LR teste), rejeitou-se a hipótese nula de que não existe diferença de grupos. Portanto, o modelo hierárquico é preferível ao modelo com apenas um nível.

Levando em consideração a variância e covariância estimadas, a correlação de efeitos aleatórios é positiva e relativamente elevada, em ambos os anos, respectivamente 0,5912 e 0,6945 . Isso indica que zonas de residência com chances acima da média de comutação via transporte coletivo (contra transporte não motorizado) tendem também a apresentar chances acima da média de escolha de transporte individual (contra transporte não motorizado). Características específicas de cada zona podem ajudar a explicar tal fato. Por exemplo, zonas mais distantes dos centros de emprego tornam menos prováveis os deslocamentos a pé ou de bicicleta.

Sobre os coeficientes de primeiro nível, é preciso ter cuidado ao interpretar os resultados, sendo a comparação restrita entre a categoria considerada (coletivo ou individual motorizado) e a categoria escolhida como base (individual não motorizado). A adição dos efeitos aleatórios de zona geográfica não altera os sinais, porém diferenças em magnitudes são observadas.

Como esperado, quanto maior a distância a ser percorrida, menores as chances relativas que o trabalhador opte por caminhar ou andar de bicicleta até o trabalho. Em ambas as especificações, e em ambos os anos, o aumento de $1 \mathrm{~km}$ na distância a ser percorrida aumenta mais de $200 \%$ as chances relativas de se escolher transporte motorizado privado ou coletivo em comparação a comutar a pé ou de bicicleta.

Analisando o horário do deslocamento, em ambos horários de pico as chances relativas do uso de transporte individual são maiores, em especial para os indivíduos que vão para o trabalho no pico da tarde, que também são afetados pelos congestionamentos. Por outro lado, no pico mais complicado (entre 6 e 10 da manhã), encontra-se o menor valor para as chances relativas de se escolher o transporte coletivo, sendo que os coeficients são não significtivos para o período da tarde.

Realizar a migração pendular aumentava as chances de o modo de transporte escolhido ser o individual em 2007, mesmo controlando pela distância comutada. Mas os demais coeficientes foram não significativos. Um migrante pendular apresenta uma probabilidade muito inferior de realizar o deslocamento a pé ou de bicicleta que um trabalhador que vive e trabalha na mesma cidade.

Em 2007, viver na capital, em comparação a outra cidade da RMSP, aumentava as chances de se escolher o transporte coletivo e não exercia influência na escolha pelo transporte privado, em comparação ao transporte não motorizado. Em 2012, o cenário muda: era maior a probabilidade de utilização do transporte coletivo, e não havia diferenças significativas com relação à escolha por transporte individual motorizado. Enquanto em São Paulo o padrão se mantém, nos outros municípios cai a probabilidade de comutar a pé ou de bicicleta ao passo que sobe a probabilidade de utilização de transporte individual privado, ultrapassando São Paulo.

Para ambos os anos, percebe-se um padrão em que homens, em comparação às mulheres, apresentam menor probabilidade de comutarem com modo coletivo e são mais 
propensos a utilizarem transporte individual privado. Vale lembrar que são incluídos controles de distância (homens comutam maiores distâncias) e também de posição na família (homens são mais preponderantes na condição de chefe). Dado que houve aumento da frota de veículos no período, pode-se conjecturar que esse aumento tenha ligação com uma maior propensão dos homens em adquirir veículo automotor próprio. Além disso, é sabido que homens são mais propensos a utilizarem motocicletas, que também teve aumento expressivo da frota no período.

Tabela 4: Escolha por Transporte - 2007 e 2012

\begin{tabular}{|c|c|c|c|c|}
\hline & \multicolumn{2}{|c|}{2007} & \multicolumn{2}{|c|}{2012} \\
\hline & Coletivo & Individual & Coletivo & Individual \\
\hline \multicolumn{5}{|c|}{ Efeitos Fixos } \\
\hline Distância em Km & $\begin{array}{c}3,429 * * * \\
(0,0767)\end{array}$ & $\begin{array}{c}3,232 * * * \\
(0,0723)\end{array}$ & $\begin{array}{c}3,446^{* * * *} \\
(0,1513)\end{array}$ & $\begin{array}{c}3,243 * * * \\
(0,1424)\end{array}$ \\
\hline \multicolumn{5}{|c|}{ Horário do deslocamento (fora de picos omitido) } \\
\hline Entre 6 e 10 da manhã & $\begin{array}{c}0,783 * * * \\
(0,0457)\end{array}$ & $\begin{array}{l}1,230 * * * \\
(0,0737)\end{array}$ & $\begin{array}{c}0,773^{*} \\
(0,0798)\end{array}$ & $\begin{array}{c}1,261^{*} \\
(0,1326)\end{array}$ \\
\hline Entre 17 e 20 horas & $\begin{array}{c}1,288 \\
(0,1908)\end{array}$ & $\begin{array}{c}1,796^{* * * *} \\
(0,2698)\end{array}$ & $\begin{array}{c}1,327 \\
(0,3656)\end{array}$ & $\begin{array}{c}1,762^{*} \\
(0,4857)\end{array}$ \\
\hline Migrante pendular? (não omitido) & $\begin{array}{c}1,071 \\
(0,1486)\end{array}$ & $\begin{array}{c}1,318^{*} \\
(0,1838)\end{array}$ & $\begin{array}{c}1,007 \\
(0,2522)\end{array}$ & $\begin{array}{c}1,153 \\
(0,2891)\end{array}$ \\
\hline Vive na capital? (não omitido) & $\begin{array}{c}1,162^{*} \\
(0,0830)\end{array}$ & $\begin{array}{c}0,901 \\
(0,0771)\end{array}$ & $\begin{array}{c}0,864 \\
(0,1433)\end{array}$ & $\begin{array}{c}0,588 * * * \\
(0,0886)\end{array}$ \\
\hline Sexo (masculino omitido) & $\begin{array}{l}1,408 * * * \\
(0,0784)\end{array}$ & $\begin{array}{c}0,587 * * * \\
(0,0332)\end{array}$ & $\begin{array}{c}1,261 * \\
(0,1369)\end{array}$ & $\begin{array}{c}0,465 * * * \\
(0,0512)\end{array}$ \\
\hline Idade & $\begin{array}{c}0,961 * \\
(0,0155)\end{array}$ & $\begin{array}{l}1,054 * * \\
(0,0173)\end{array}$ & $\begin{array}{c}1,005 \\
(0,0308)\end{array}$ & $\begin{array}{l}1,107 * * \\
(0,0344)\end{array}$ \\
\hline Idade ao quadrado & $\begin{array}{l}1,001 * * \\
(0,0002) \\
\end{array}$ & $\begin{array}{c}1,000^{*} \\
(0,0002) \\
\end{array}$ & $\begin{array}{c}1,000 \\
(0,0004) \\
\end{array}$ & $\begin{array}{l}0,999 * * \\
(0,0004) \\
\end{array}$ \\
\hline \multicolumn{5}{|c|}{ Grau de instrução (até ensino primário incompleto omitido) } \\
\hline Primário completo e até fundamental incompleto & $\begin{array}{c}1,225 \\
(0,1544)\end{array}$ & $\begin{array}{l}1,475 * * \\
(0,2013)\end{array}$ & $\begin{array}{c}0,971 \\
(0,2455)\end{array}$ & $1,318(0,3496)$ \\
\hline Fundamental completo e até médio incompleto & $1,292 *(0,1612)$ & $\begin{array}{c}1,677 * * * \\
(0,2257)\end{array}$ & $\begin{array}{c}1,244 \\
(0,3085)\end{array}$ & $\begin{array}{c}1,814^{*} \\
(0,3085)\end{array}$ \\
\hline Médio completo e até superior incompleto & $\begin{array}{c}1,988 * * * * \\
(0,2350)\end{array}$ & $\begin{array}{c}2,429 * * * \\
(0,3100)\end{array}$ & $\begin{array}{c}1,611^{*} \\
(0,3100)\end{array}$ & $\begin{array}{c}2,453 * * * \\
(0,6149)\end{array}$ \\
\hline Superior completo ou mais & $\begin{array}{c}1,986 * * * \\
(0,2554)\end{array}$ & $\begin{array}{c}3,984 * * * \\
(0,5421)\end{array}$ & $\begin{array}{c}1,398 \\
(0,3666)\end{array}$ & $\begin{array}{c}3,627 * * * \\
(0,9788)\end{array}$ \\
\hline \multicolumn{5}{|c|}{ Situação familiar (Pessoa responsável omitido) } \\
\hline Cônjuge/Companheiro(a) & $\begin{array}{c}1,012 \\
(0,0711)\end{array}$ & $\begin{array}{c}0,954 \\
(0,0675)\end{array}$ & $\begin{array}{c}1,224 \\
(0,1624)\end{array}$ & $\begin{array}{c}0,841 \\
(0,1136)\end{array}$ \\
\hline Filho(a)/Enteado(a) & $\begin{array}{c}1,087 \\
(0,0835)\end{array}$ & $\begin{array}{l}0,775 * * \\
(0,0603)\end{array}$ & $\begin{array}{c}1,837 * * * \\
(0,2739)\end{array}$ & $\begin{array}{c}0,966 \\
(0,1446)\end{array}$ \\
\hline Outro parente & $\begin{array}{c}0,849 \\
(0,0844)\end{array}$ & $\begin{array}{c}0,405 * * * \\
(0,0423)\end{array}$ & $\begin{array}{c}1,453 \\
(0,2929)\end{array}$ & $\begin{array}{c}0,597 * \\
(0,1240)\end{array}$ \\
\hline Logaritmo da renda domiciliar & $\begin{array}{c}1,159 * * * \\
(0,0488)\end{array}$ & $\begin{array}{c}3,432 * * * \\
(0,1482)\end{array}$ & $\begin{array}{c}1,047 \\
(0,0870)\end{array}$ & $\begin{array}{c}2,788 * * * \\
(0,2318)\end{array}$ \\
\hline Constante & $\begin{array}{c}0,028 * * * \\
(0,0129)\end{array}$ & $\begin{array}{c}0,000 * * * \\
(0,0000)\end{array}$ & $\begin{array}{c}0,044 * * * * \\
(0,0398)\end{array}$ & $\begin{array}{r}0,000^{* * * *} * \\
(0,0000)\end{array}$ \\
\hline \multicolumn{5}{|c|}{ Efeitos aleatórios } \\
\hline Variância (constante) & 0,0983 & 0,2655 & 0,0965 & 0,0650 \\
\hline Covariância (Individual, Coletivo) & \multicolumn{2}{|c|}{0,0955} & \multicolumn{2}{|c|}{0,0550} \\
\hline Log-Verossimilhança & \multicolumn{2}{|c|}{$-18.169,52$} & \multicolumn{2}{|c|}{$-5385,20$} \\
\hline
\end{tabular}




\begin{tabular}{l|c|c}
\hline LR teste(3) & 422,28 & 104,74 \\
\hline $\mathrm{N}$ & 28.197 & 8.194 \\
\hline \hline
\end{tabular}

Nota: Transporte motorizado é a categoria omitida

$*$ significativo a $5 \%$; ** significativo a $1 \%$; *** significativo a $0,1 \%$.

Fonte: elaboração própria a partir dos resultados das estiamtivas.

Em 2007, para ambas as especificações, idade afeta negativamente as chances de que um trabalhador escolha o modo coletivo em comparação ao modo não motorizado, enquanto indivíduos mais velhos apresentam maiores chances de escolher o modo individual privado em comparação ao modo não motorizado. Em 2012, o coeficiente para idade foi não significativo para o modo coletivo.

Quanto maior a educação formal de um trabalhador, menor a probabilidade que ande ou utilize bicicleta para o trabalho. Trabalhadores com ensino superior completo apresentam elevadas chances relativas de optarem pelo transporte individual, fato observado também para outros trabalhadores com pelo menos ensino médio compelo, mas em menor grau. Lembrando que o nível educacional no Brasil aumentou no período, observa-se uma homogeneização nas chances relativas de escolha entre 2007 e 2012. Esse resultado pode ser animador, pois sabe-se que em países desenvolvidos, é comum os mais ricos utilizarem transporte público. Por outro lado, todos os grupos de menor escolaridade apresentaram um aumento da probabilidade de utilização de transporte privado. Esse resultado pode ser visto como oriundo das melhorias de renda e também do maior acesso a crédito. Porém, liga um alerta, pois mostra que os trabalhadores continuam trocando o transporte público pelo privado quando adquirem condições para tal. Para que a primeira mudança continue ocorrendo, e a segunda deixe de ocorrer, é preciso investir na melhoria não apenas do transporte público, como também melhorar a acessibilidade aos locais de embarque.

Com relação à situação familiar, observa-se que os filho(as)/enteado(a)s eram menos propensos ao deslocamento por modo individual em 2007, e por modo coletivo em 2012, na comparação com os responsáveis pelo domicílio. Todos os resultados para conjuges foram não significativos, indicando que as diferenças observadas na análise descritiva são controladas pelas outras variáveis no modelo.

Finalizando a análise da Tabela 4, a renda domiciliar é um dos principais componentes que explicam a escolha por transporte individual. Observando ambas as especificações com diferenças nos efeitos aleatórios, um aumento de $1 \%$ na renda domiciliar aumentou em 2,43\%, aproximadamente, a razão de riscos relativos de um trabalhador optar pelo modo individual em comparação ao modo não motorizado, em 2007, e, para 2012, o aumento foi de 1,8, aproximadamente. Apesar de muito importante para a escolha do tipo de transporte, sua importância caiu no período. Não obstante, enquanto em 2007 o aumento de $1 \%$ na renda domiciliar foi aproximadamente 0,11 , a razão entre as probabilidades de utilização de transporte coletivo e não motorizado deixou de ser significativa em 2012. 


\subsection{Estimativas - Tempo Comutado}

Após estimada a equação de escolha por modal de transporte, o segundo passo é estimar os efeitos sobre a duração dos trajetos diários. Como mencionado na seção metodológica, os valores preditos gerados após a estimação do modelo logit multinomial são incluídos na equação a seguir. São testados modelos com apenas intercepto aleatório e um modelo com coeficiente aleatório (modo coletivo e modo individual).

Percebe-se que, apesar da modelagem indicada ser a multinível (em todos os modelos o teste da razão de verossimilhança indica a melhora do modelo com a inclusão dos efeitos aleatórios). Em 2007, apenas 2,4\% da variação no tempo de comutação é explicada por diferenças nas áreas de origem. Em 2012, o efeito é ainda mais reduzido, com menos de $1 \%$.

Começaremos pelas análises das covariâncias estimadas. Em todas as estimativas, não há mudanças nos sinais das covariâncias, sinal de robustez dos modelos. Assim como na análise da escolha por transporte, o sinal positivo da covariância entre coletivo e individual indica que, zonas geográficas com alta probabilidade de que os trabalhadores escolham transporte privado para a comutação, também apresentam alta probabilidade de os trabalhadores escolherem o transporte coletivo. Em outras palavras, existem similaridades de segundo nível, não mensuráveis, entre as alternativas (STEELE, 2013). Já os sinais negativos das covariâncias entre a constante e os modos coletivo e individual indicam que, em zonas geográficas com tempo médio de comutação acima da média (intercepto elevado), o efeito da escolha do modo coletivo ou individual é reduzido. Áreas com elevado percentual de tempo de comutação já apresentam percentuais elevados de utilização de ônibus e transporte privado. Logo, o efeito da utilização sobre o tempo é reduzido.

Analisando os efeitos fixos, em 2007, o aumento de uma unidade na probabilidade predita de utilizar o modo coletivo, aumenta em 1,79\% o tempo comutado, enquanto o aumento de uma unidade na probabilidade predita de utilizar o modo individual aumenta em 1,01\% o tempo comutado, controlando-se pela distância comutada. Porém, em 2012 os sinais se mantêm e os efeitos são ainda maiores. Dado que a estimativa está controlada pela distância, esse aumento, pode ser um indicador de piora da mobilidade via modais motorizados.

Como esperado, a distância comutada exerce influência positiva sobre o tempo gasto com comutação diária. Em 2007, aumentos de um quilômetro na distância comutada acrescem em aproximadamente 4\% o tempo comutado, enquanto em 2012 esse aumento é de aproximadamente 3\%. Portanto, houve diminuição da importância da distância para explicar tempo de comutação no período.

Analisando o horário de deslocamento, em 2007, comutar entre 6 e 10 da manhã, em comparação a comutar depois das 10 até às 17 e depois das 20 horas até 6 da manhã, aumenta em aproximadametne 3,8\% o tempo comutado. A categoria "Entre 17 e 20 
horas" não é significativa em 2007 e $2012 .{ }^{3}$ Novamente, há aumento do tempo comutado quando consideramos as estimativas de 2012. Para 2012, comutar entre 6 e 10 da manhã em comparação a comutar depois das 10 até às 17 e depois das 20 horas até 6 da manhã, aumenta em aproximadamente 5,8\% o tempo comutado, mais um indício da piora em termos de mobilidade na RMSP.

Tabela 5: Estimativa dos Determinantes de Duração dos Trajetos

\begin{tabular}{|c|c|c|c|c|}
\hline & \multicolumn{2}{|c|}{2007} & \multicolumn{2}{|c|}{2012} \\
\hline & Int. aleat. & Coef. aleat. & Int. aleat. & Coef. aleat. \\
\hline Predito do modo coletivo & $\begin{array}{l}1,843 * * * \\
(0,0155)\end{array}$ & $\begin{array}{l}1,789 * * * \\
(0,0323)\end{array}$ & $\begin{array}{l}2,229 * * * \\
(0,0463)\end{array}$ & $\begin{array}{l}2,078 * * * \\
(0,0740)\end{array}$ \\
\hline Predito do modo individual & $\begin{array}{l}1,055^{* * * *} \\
(0,0198)\end{array}$ & $\begin{array}{l}1,008 * * * \\
(0,0312)\end{array}$ & $\begin{array}{l}1,395 * * * \\
(0,5500)\end{array}$ & $\begin{array}{l}1,333 * * * \\
(0,0771)\end{array}$ \\
\hline Distância em Km & $\begin{array}{l}0,036^{* * * *} \\
(0,0006)\end{array}$ & $\begin{array}{l}0,039 * * * \\
(0,0011)\end{array}$ & $\begin{array}{l}0,0291 * * * \\
(0,0013) \\
\end{array}$ & $\begin{array}{l}0,032 * * * * \\
(0,0019)\end{array}$ \\
\hline \multicolumn{5}{|c|}{ Horário do deslocamento (fora de picos omitido) } \\
\hline Entre 6 e 10 da manhã & $\begin{array}{l}0,047 * * * \\
(0,0103)\end{array}$ & $\begin{array}{l}0,038 * * \\
(0,0132)\end{array}$ & $\begin{array}{l}0,0576^{* *} \\
(0,0195)\end{array}$ & $\begin{array}{l}0,059^{*} \\
(0,0234)\end{array}$ \\
\hline Entre 17 e 20 horas & $\begin{array}{l}-0,016 \\
(0,0220)\end{array}$ & $\begin{array}{l}-0,005 \\
(0,0344)\end{array}$ & $\begin{array}{l}-0,072 \\
(0,0637)\end{array}$ & $\begin{array}{l}-0,016 \\
(0,0666)\end{array}$ \\
\hline Sexo (masculino omitido) & $\begin{array}{l}-0,016^{* * *} \\
(0,0061)\end{array}$ & $\begin{array}{l}-0,019 \\
(0,0102)\end{array}$ & $\begin{array}{l}-0,016 \\
(0,0188)\end{array}$ & $\begin{array}{l}0,008 \\
(0,0206)\end{array}$ \\
\hline Idade & $\begin{array}{l}-0,001 * * \\
(0,0003)\end{array}$ & $\begin{array}{l}-0,001^{*} \\
(0,0004) \\
\end{array}$ & $\begin{array}{l}0,026 * * * \\
(0,0035)\end{array}$ & $\begin{array}{l}0,000 \\
(0,0008)\end{array}$ \\
\hline Idade ao quadrado & $\begin{array}{l}-0,000 * * * \\
(0,0000)\end{array}$ & $\begin{array}{l}-0,000 * * * \\
(0,0000)\end{array}$ & $\begin{array}{l}-0,000 * * * \\
(0,0000)\end{array}$ & $\begin{array}{l}-0,000 * * * \\
(0,0000)\end{array}$ \\
\hline Constante & $\begin{array}{l}2,038 * * * \\
(0,0280)\end{array}$ & $\begin{array}{l}2,065 * * * \\
(0,0315)\end{array}$ & $\begin{array}{l}1,279 * * * \\
(0,0656)\end{array}$ & $\begin{array}{l}1,812 * * * \\
(0,0639)\end{array}$ \\
\hline Variância (constante) & $0,008 * * *$ & $0,122 * * *$ & $0,003 * * *$ & $0,047 * * *$ \\
\hline Variância (modo coletivo) & & $0,180 * * *$ & & $0,062 * * *$ \\
\hline Variância (modo individual) & & $0,153 * * *$ & & $0,039 * * *$ \\
\hline Covariância (coletivo, individual) & & $0,072 * * *$ & & $0,002 * * *$ \\
\hline Covariância (coletivo, constante) & & $-0,061 * * *$ & & $-0,003 * * *$ \\
\hline Covariância (individual, constante) & & $-0,018 * * *$ & & $-0,002 * * *$ \\
\hline Variância (residual) & $0,322 * * *$ & $0,309 * * *$ & $0,337 * * *$ & $0,334 * * *$ \\
\hline Log-Verossimilhança & $-24.219,48$ & $-23.957,02$ & $-7.191,20$ & $-7.172,76$ \\
\hline LR teste(5) & \multicolumn{2}{|c|}{524,92} & \multicolumn{2}{|c|}{36,88} \\
\hline $\mathrm{N}$ & \multicolumn{2}{|c|}{28.197} & \multicolumn{2}{|c|}{8.282} \\
\hline
\end{tabular}

Fonte - Elaboração própria a partir dos dados.

${ }^{3}$ É importante frisar que se trata apenas dos deslocamentos casa-trabalho, ou seja, o trajeto de ida. É provável que estes indivíduos enfrentem o contra-fluxo de veículos, por isso a menor importância. 


\section{Considerações Finais}

O presente estudo investigou a relação entre tipo de transporte utilizado, distância percorrida e tempo comutado na Região Metropolitana de São Paulo. Os dados utilizados foram da Pesquisa Origem-Destino de 2007 e da Pesquisa de Mobilidade 2012.

Em função das correlações presentes nas relações supracitadas aplicou-se a modelagem de equações estruturais aos dados. Além disso, dado que o efeito de características das zonas geográficas de origem (residência) e destino (trabalho) pode afetar tanto a escolha pelo tipo de transporte quanto o tempo comutado, aplicou-se modelagem hierárquica aos dados.

Os achados gerais indicaram que: i) decaiu, no período, o percentual de indivíduos que comutam curtas distâncias, tendo aumentado o percentual daqueles que comutam longas distâncias; ii) houve queda t do percentual dos que gastam até 30 minutos com comutação, com consequente aumento do percentual daqueles que gastam mais uma hora no deslocamento de casa até o trabalho; iii) trabalhadores que utilizam transporte coletivo foram os que mais gastam tempo até o trabalho, seguidos pelos que utilizam automóveis; iv) houve crescimento da utilização de veículos privados para o deslocamento, o que pode ter contribuído para a piora das condições do trânsito na região.

Os resultados indicaram, para a estimativa de escolha por tipo de transporte, que zonas geográficas em que os indivíduos apresentam chances acima da média de utilizarem transporte individual privado, também apresentam chances elevadas de utilização de transporte público coletivo. Isso pode ser um sinal de que estas regiões estejam localizadas longe dos centros de negócios e, como a renda domiciliar é um dos principais fatores que explicam a escolha pelo transporte individual motorizado em detrimento do transporte não motorizado, os resultados vão ao encontro dos achados de Zegras (2010).

Em resumo: i) em horários de pico, com a redução pela escolha do transporte coletivo, houve popularização do transporte privado; ii) migrantes pendulares apresentaram elevada probabilidade de escolher o transporte coletivo e probabilidade próxima de zero de escolherem comutar a pé; iii) mulheres se mostraram mais propensas a utilizarem transporte não motorizado e coletivo que homens; iv) trabalhadores com mais instrução formal, em especial aqueles com ensino superior completo, possuem maior probabilidade de opção pelo transporte privado; v) e, por fim, analisando o arranjo familiar, a pessoa responsável pelo domicílio é a mais provável de utilizar transporte privado, enquanto filho(a)s apresentaram elevada probabilidade de utilizarem transporte coletivo e cônjuges de caminharem ou utilizarem bicicleta para o trabalho.

Considerando as estimativas para tempo comutado, os principais resultados mostraram que:

aumentos na probabilidade predita de utilização de transporte privado ou público aumentam o tempo comutado, sendo o efeito maior para o coletivo. Como esperado, quanto maior a distância maior o tempo comutado, porém o efeito caiu no período. Comutar no horário de pico aumenta em torno de $6 \%$ o tempo gasto, sendo o efeito mais elevado em 2012. 
Dado que a utilização de veículo privado é maior em horários de pico, enquanto a utilização de transporte público é menor em tais horários, uma forma de tentar melhorar a questão de acessibilidade seria tornar, de alguma maneira, o transporte coletivo mais atrativo para as pessoas que utilizam carro, principalmente nos horários de pico. Uma forma é a melhoria da acessibilidade (NELSON, 1977; VILLAÇA, 2001) aos locais de embarque e desembarque, com ênfase na segurança no trajeto. Outra forma é a cobrança de pedágios. Hensher e Rose (2007) mostram que, na Região Metropolitana de Sidney, na Austrália, pedágios reduzem em até $10 \%$ a utilização de veículos privados para descolamento por motivo trabalho e em até $20 \%$ para deslocamentos de outros tipos. Outra alternativa, passa pela continuação de expansão de faixas exclusivas para ônibus, medida que vem sendo implementada desde 2013, na capital paulista. A primeira alternativa poderia diminuir a utilização de carros via aumento dos custos de utilização dos mesmos, enquanto a segunda poderia, ao diminuir o tempo médio de deslocamento via ônibus, incentivar pessoas a deixarem de utilizar carros e utilizarem transporte público. O projeto foi batizado de "Dá Licença para o ônibus" e almeja reduzir o tempo das viagens de ônibus.

Caso não seja possível convencer os trabalhadores a deixarem de utilizar carros, uma possível solução é a implementação, nos horários de pico, de pistas exclusivas para carros cheios (High-occupancy vehicle lane), como já é aplicado na Austrália, nos Estados Unidos, Canadá, parte da Europa, China, entre outros. Incentivar as pessoas a darem carona pode diminuir os veículos em circulação, contribuindo para melhorias no trânsito.

Por fim, como desdobramento desse estudo, pode-se analisar a comutação de volta para casa. Dados os resultados apresentados acima, podem surgir situações em que o modo de transporte seja diferente na ida e na volta. Por exemplo, o indivíduo pode optar em caminhar até o trabalho e voltar de ônibus ou metrô para casa, dependendo dos horários dos deslocamentos.

\section{Referências}

BOJE, A.; OTT, I.; STILLER, S. Development Perspectives for the City of Hamburg: Migration, commuting, and specialization (No. 1-23). HWWI Policy Paper, 2010.

BREHENY, M. Counter-Urbanisation and Sustainable Urban Forms. In: BROTCHIE, J.; BATTY, M.; BLAKELY, E. Cities in Competition: Productive and Sustainable Cities for the 21st Century. 1995.

BRUECKNER, J. K. Lectures on Urban Economics. MIT Press, 2011. DOI: https://doi.org/10.1093/jeg/lbs030

CAMAGNI, R.; GIBELLI, M. C.; RIGAMONTI, P. Urban Mobility and Urban Form: the social and environmental costs of different patterns of urban expansion. Ecological Economics, v. 40, n. 2, 199-216, 2002. 
DOI: http://dx.doi.org/10.1016/S0921-8009(01)00254-3

CAMERON, A. C.; TRIVEDI, P. K. Microeconometrics: Methods and applications. Cambridge university press, 2005.

CARVALHO, C.; PEREIRA, R. Indicadores de Mobilidade Urbana da Pnad 2012. Instituto de Pesquisa Econômica Aplicada (IPEA), 2013.

CHARRON, M. From Excess Commuting to Commuting Possibilities: More extension to the concept of excess commuting. Environment and Planning A, v. 39, n. 5, p. 12381254, 2007.

Da Cruz, A. T. D. Suburbanização, Branqueamento e Urbanidades na Reconfiguração Socioterritorial do Rio de Janeiro Republicano. Cadernos IPPUR, v. 73, 2007.

CHEN, X.; LIU, X.; LI, F. Comparative Study on Mode Split Discrete Choice Models. Journal of Moder Transportation, v. 21, n. 4, p. 266-272, 2013.

DOI: https://doi.org/10.1007/s40534-013-0028-5

DAHLBERG, M.; EKLÖF, M. Relaxing the IIA Assumption in Locational Choice Models: A comparison between conditional logit, mixed logit, and multinomial probit models. National Ekonomiska Institutionen, 2003.

EFRON, B.; TIBSHIRANI, R. J. An Introduction to the Bootstrap. CRC Press, 1994.

GLAESER, E. L.; KAHN, M. E.; RAPPAPORT, J. Why do the Poor Live in Cities? The role of public transportation. Journal of Urban Economics, v. 63, n. 1, p. 1-24, 2008. DOI: https://doi.org/10.1016/j.jue.2006.12.004

HADDAD, E. A.; HEWINGS, G. J.; PORSSE, A. A.; VAN LEEUWEN, E. S.; VIEIRA, R. S. The Underground Economy: Tracking the higher-order economic impacts of the São Paulo subway system. Transportation Research Part A: Policy and Practice, v. 73, p. 18-30, 2015.

HENSHER, D. A.; ROSE, J. M. Development of Commuter and Non-Commuter Mode Choice Models for the Assessment of New Public Transport Infrastructure Projects: A case study. Transportation Research Part A: Policy and Practice, v. 41, n. 5, p. 428443, 2007. DOI: https://doi.org/10.1016/j.tra.2006.09.006

KWAN, M. P. Gender Differences in Space-Time Constraints. Area, v. 32, n. 2, p. $145-$ 156, 2000. DOI: https://doi.org/10.1111/j.1475-4762.2000.tb00125.x

LE, A. T.; MILLER, P. W. Satisfaction with Time Allocations within the Family: The role of family type. Journal of Happiness Studies, v. 14, n. 4, p. 1273-1289, 2013. DOI: https://doi.org/10.1007/s10902-012-9381-z

LEVY, C. Travel Choice Reframed: "Deep distribution" and gender in urban transport. Environment and Urbanization, v. 25, n. 1, p. 47-63, 2013.

DOI: https://doi.org/10.1177/0956247813477810 
MASSER, I.; SVIDÉN, O.; WEGENER, M. The Geography of Europe's Futures. The Geography of Europe's Futures, 1992.

METRÔ. Pesquisa Origem e Destino da Região Metropolitana de São Paulo - 2007: Síntese das Informações Pesquisa Domiciliar. São Paulo, 2008.

MOGRIDGE, M. J. H. Transport, Land Use and Energy Interaction. Urban Studies, v. 22, n. 6, p. 481-492, 1985. DOI: https://doi.org/10.1080/00420988520080851

NÆSS, P. Residential Location Affects Travel Behavior: But how and why? The case of Copenhagen metropolitan area. Progress in Planning, v. 63, n. 2, p. 167-257, 2005. DOI: https://doi.org/10.1016/j.progress.2004.07. 004.

NÆSS, P.; JENSEN, O. B. Urban Structure Matters, Even in a Small Town. Journal of Environmental Planning and Management, v. 47, n. 1, p. 35-57, 2004.

DOI: https://doi.org/10.1080/0964056042000189790

NELSON, J. P. Accessibility and the Value of Time in Commuting. Southern Economic Journal, p. 1321-1329, 1977. DOI: https://doi.org/10.2307/1057789

NIJKAMP, P.; RIENSTRA, S. A. Sustainable Transport in a Compact City. The Compact City: A sustainable urban form, p. 190-199, 1996.

OJIMA, R.; MARANDOLA JR, E.; PEREIRA, R. H. M.; DA SILVA, R. B. O Estigma de Morar Longe da Cidade: Repensando o consenso sobre as" cidades-dormitório" no Brasil. Cadernos Metrópole, v. 12, n. 24, p. 395-415, 2010.

PLAUT, P. O. Non-Motorized Commuting in the US. Transportation Research Part D: Transport and Environment, v. 10, n. 5, p. 347-356, 2005.

DOI: http://dx.doi.org/10.1016/j.trd.2005.04.002

QUIROS, T. P.; MEHNDIRATTA, S. R.; OCHOA, M. C. Gender, Travel and Job Access: Evidence from Buenos Aires gender and mobility. The difference is the speeds. Washington, DC: World Bank, 2014. Retrieved from http://siteresources.worldbank.org/INTURBANTRAN SPORT/Resources/2014-Feb-5Gender-and-Mobility. pdf

RASBASH, J. Module 4: Multilevel structures and classifications. LEMMA VLE, Centre for Multilevel Modelling, University of Bristol, 2008.

RIBEIRO, L. L. Pobreza: Da insuficiência de renda à privação de tempo. Revista de Desenvolvimento Econômico, v. 14, n. 25, 2012.

STEELE, F. Module 5: Introduction to multilevel modelling concepts. LEMMA (Learning Environment for Multilevel Methodology and Applications), Centre for Multilevel Modelling, University of Bristol, 2008.

STEELE, F. Single-level and Multilevel Models for Nominal Responses: Concepts. lemma vle module 10. LEMMA VLE Module 10, n/a, n. 10, 2013. 
TABACHNICK, B. G.; FIDELL, L. S. Using Multivariate Statistics. Boston. MA: Allyn and Bacon, 5, 2007.

URIARTE, A. M. L. Estrutura Urbana e Viagens a Pé (Doctoral dissertation, Tese de Doutorado em Engenharia da Produção. Universidade Federal do Rio Grande do Sul. UFRGS), 2012.

VILLAÇA, A. F. O Espaço Intra-Urbano no Brasil. São Paulo: Estúdio Nobel, São Paulo, 2001.

ZEGRAS, C. The Built Environment and Motor Vehicle Ownership and Use: Evidence from Santiago de Chile. Urban Studies, v. 47, n. 8, p. 1793-1817, 2010.

DOI: https://doi.org/10.1177/0042098009356125

WERNER, C.; SCHERMELLEH-ENGEL, K. Structural Equation Modeling:

Advantages, challenges, and problems. Introduction to Structural Equation Modeling with LISREL, 2009. 